\title{
Minor Salivary Gland Undifferentiated
} Carcinoma

National Cancer Institute

\section{Source}

National Cancer Institute. Minor Salivary Gland Undifferentiated Carcinoma. NCI

Thesaurus. Code C5954.

A carcinoma that affects the minor salivary glands and is characterized by the presence of undifferentiated, anaplastic malignant epithelial cells. 